\section{A MORE OBJECTIVE APPROACH FOR SELECTING THE JOURNAL TO WHICH ONE SUBMITS A MANUSCRIPT}

\section{Introduction}

There is considerable variability in the methods authors use to identify journals for manuscript submission, and this process may be difficult for some junior (and even some more senior) investigators. Given the wide range of potential journal-candidates for any article being submitted, we believed that a gridinstrument might help authors explicitly set journal selection priorities that reflect realities, hopes, and expectations. Our model is based on five main steps for authors. Step one: authors identify individualized criteria for submission. We produced a research- and pragmatically-based model list of criteria and subcriteria, and subjected it to a modified Delphi process with participants that ranged from junior investigators to seasoned editors. Our proposed list for authors' initial consideration includes: journal prestige, likelihood of manuscript acceptance, quality of review, rapidity of turnaround, and intangibles. Step two: authors weight criteria by importance/priority for that particular author for that particular manuscript. Step three: select potential candidate journals. Step four: score each criterion on a grid for each candidate journal. Step five: calculate scores, and rank journals. All five steps are explained in greater detail in our full model description, and examples of model grid implementation are provided.

This method is rapid and can be engaging, and could make the submission process more efficient and effective. It should be particularly useful for those authors with little experience or external guidance, and for more senior authors who wish to make their journal selection process more explicit.

\section{A five-step analytic model}

Authors' motives and methods for choosing a goal journal for manuscript submission vary.(1) Such decisions are probably typically made implicitly and informally, with a view to achieving the highest possible prestige, commensurate to the quality of the proposed manuscript.(1) Manuscript submission is accompanied by much uncertainty on how the material will be judged (2). Considering the vast array of existing journals, and hence the wide range of potential journals (and editorial reactions) for any article being submitted, it might be beneficial to identify a methodological instrument that helps authors explicitly and parsimoniously set journal selection priorities, in keeping with their own expectations. Such quantitative priority setting would enable authors to both structure
1. Identify the priority setting criteria

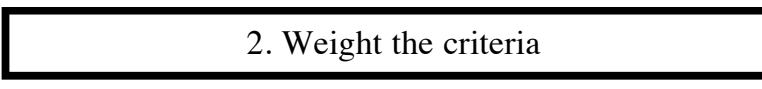

3. Select the candidate journals

4. Rate each criterion

5. Calculate priorities

Figure 1. Overview of the journal selection priority-setting process

and refine their thinking about this often subjective topic.

The model is based on five main steps (Figure 1) that are outlined below.

Step 1: Identifying the main priority-setting criteria.

The first step is to select which criteria to consider in deciding where to submit an article. Our model is outlined below, but authors should modify this model with their own procedures and considerations. To create our list, we produced a provisional list of criteria and subcriteria taken from prior work (1) and guided pragmatically. The list was submitted to 16 colleagues from various nationalities (Italy, Australia, USA, Russia, UK) and healthcare domains, who had in common experience as authors in national and international peer-reviewed journals. Many of these individuals had also served as reviewers and editors, and some were the junior faculty who are potential users of this method. Using the received observations, we constructed a final list, and propose including the following five criteria (Table 1): "Prestige", "Likelihood of acceptance", "Quality of review", "Rapidity of turnaround" and "Intangibles".

\section{Step 2: Weighting the criteria}

In addition to selecting criteria, weighting the value of each assigned criterion also drives the outcome. In using our proposed method, authors would need to attentively assess the quality of their work, the rapidity with which they desire publication versus their need for prestigious publications, etc., in accordance with the 
Table 1.List of proposed priority-setting criteria

\begin{tabular}{|c|c|}
\hline Criterion & Definition \\
\hline Prestige & $\begin{array}{l}\text { The importance attributed to a } \\
\text { particular journal. }\end{array}$ \\
\hline Likelihood of acceptance & $\begin{array}{l}\text { Perception of the probability of a } \\
\text { certain article being published in a } \\
\text { certain journal }\end{array}$ \\
\hline Quality of review & $\begin{array}{l}\text { Perception of the fairness of the } \\
\text { reviewer process and that, } \\
\text { whatever the outcome, there will } \\
\text { be a benefit in terms of useful } \\
\text { suggestions. }\end{array}$ \\
\hline Rapidity of turnaround & $\begin{array}{l}\text { Speed with which the editor of a } \\
\text { journal passes } \\
\text { judgement on an article }\end{array}$ \\
\hline Intangibles & $\begin{array}{l}\text { Perception of other mainly } \\
\text { subjective advantages, such as } \\
\text { preference for a certain journal, } \\
\text { the need to diversify one's } \\
\text { production, } \\
\text { acquaintance with an editor, etc. }\end{array}$ \\
\hline
\end{tabular}

criteria and subcriteria listed in step 1. The author should weight each criterion on a scale of 0 to 10 , conforming with the above considerations. The criterion deemed most important by the author is assigned a value of 10 and the other criteria are rated accordingly. The scale is a rational scale, and the importance of the various criteria are represented proportionally, i.e. a value of 4 corresponds to an importance rating half the value of 8 and twice the value of 2 . Decimal fractions of the points on the scale can also be used. A weight of 0 signifies that zero importance is attributed to that particular criterion for that particular manuscript. If there is more than one author, scoring could be conducted via a simplified two-round delphi method in which authors iteratively discuss (either electronically or through other media) and achieve consensus on their reasons for assigning particular weights. Scoring likely should be independent in the first round, but each author may revise his/her ratings on being informed (perhaps in aggregate, anonymous form) of the other authors' scores. A final determination could be made in a second round, with a decision created using consensus, a mean of authors' ratings, or other criteria.

\section{Step 3: Selecting the candidate journals}

The choice of candidate journals chiefly depends on an assessment of the manuscript and its prospects, the authors' personal objectives, and the objectives of the institutions for which the researchers work. The task is to reduce the extensive array of journals published throughout the world to a list of desirable candidates for subsequent ranking. A list may be generated from the authors' familiarity (keeping files on experiences with journals may help), colleagues' knowledge, a physical search in a local library, or via the Internet. One easily accessible source, for instance, is that of the journals listed by the main databases (3) or leading Impact Factor (IF) calculating companies (4), which often provide a service online and/or the option of receiving a free sample issue.

\section{Step 4: Rating each criterion \\ GENERAL CONSIDERATIONS}

Most criteria proposed in this article require substantial subjective assessment, with only rapidity of turnaround and prestige (through using a journal's IF or Immediacy Index or readership composition) being more heavily based on objective elements. Each criterion's score should be represented on a scale of 0 to 10 , identifying for each criterion the highest-ranking journal and giving it a rating of 10 . Other journals will then be given a score directly or inversely proportional to that of the best journal. For example, if three journals $(a, b, c)$ typically present a turnaround of 2 (a), 4 (b) and 10 weeks (c), the score given to the "Turnaround rapidity" criterion will be 10 for journal (a), which has the greatest rapidity. The score for journal $b$ will be calculated by solving for $\mathrm{x}$ : a score of $\mathrm{x}$ is to a score of 10 as the inverse of 4 weeks is to the inverse of 2 weeks (i.e. $\mathrm{x}: 10=1 / 4: 1 / 2$; or $\mathrm{x}=5$ ) and the score for journal $\mathrm{c}$ by the formula $\mathrm{x}: 10=1 / 10: 1 / 2$ (i.e. 2). Some readers may find it easier to consider score calculation in the following way, solving for $\mathrm{x}$ : for journal $\mathrm{b}$, a score of $\mathrm{x}$ (for journal b) is to a score of 10 (for journal a) as (using the inverse proportion, since a higher number of weeks is a worse outcome) 2 weeks is to 4 weeks (i.e. $\mathrm{x} / 10=2 / 4$; or $\mathrm{x}=5$ ) and the score for journal $\mathrm{c}$ by the formula $\mathrm{x} / 10=2 / 10$ (i.e. 2 ). Where there is more than one author, the delphi methodology described in step 2 may be used.

\section{CRITERION 1: PRESTIGE}

Definition: The importance attributed to a particular journal.

Specific considerations: A journal's prestige generally depends on reputation, reliability, circulation size, availability, and news coverage. There are somewhat objective methods for the measurement of prestige that rely mainly on citations in scientific journals; while these have been challenged and require critical, cautious adoption, they form a useful guide. The main methods of this kind are the Impact Factor (IF), measuring the 
frequency with which the "average article" in a journal has been cited in a particular year after publication, and the Immediacy Index, which considers citations made during the publication year of the quoted items. Another objective subcriterion is journal circulation, which can be measured by number of copies and readership estimates. The author may also be interested in impact via mass media and hence the level of attention paid to journals by the main press agencies. And prestige must be set in the context of specialty, particular objectives, and geography. For example, a laboratorian may prefer to publish a certain work in a journal from his/her own field rather than in a general medicine journal, even if the latter has a higher IF. Similarly, a European author might prefer to publish a work in a good national peerreviewed journal than in a more renowned international one, bearing in mind the English-language barriers experienced in some countries and the author's desire for use/recognition of the work in their home country. In sum, the "prestige" criteria consider the relationship between perceived journal quality and appeal, and the ensuing personal and/or institutional benefits.

Instructions: A subjective assessment must be made for each journal on a scale of 0 to 10 that considers such factors as reputation, reliability, circulation, availability, media coverage, and IF. The journal considered to be most prestigious should be assigned a score of 10 , and the other journals proportionally lower scores. Where consideration is limited to just the IF, we are faced with an objective criterion. In this case, the journal with the highest IF will be given a score of 10 and the other journals a proportionally lower score in relation to their respective IFs. Let's suppose, for example, that there are three candidate journals: BMJ, Annals of Internal Medicine and New England Journal of Medicine, for which the IFs in 2000 were 5.331, 9.833 and 29.512, respectively. In this case, the New England Journal of Medicine will be assigned a criterion score of 10, BMJ a score of 2 (by approximation), derived by calculating the proportion 29.512:10=5.331:x, and the Annals of Internal Medicine a score of 3 (by approximation), derived by calculating the proportion $29.512: 10=9.833: \mathrm{x}$.

Data sources: IF values are published annually by the Journal of Citation Reports (JCR) of the Institute for Scientific Information (ISI). The report may be purchased from the ISI, or may be consulted at many medical libraries. As for subjective assessment, subcriteria might include prestige assigned to a journal by (a) colleagues at one's institution, (b) colleagues outside one's institution in one's field, (c) other colleagues outside one's discipline, (d) one's Chair, (e) the promotions committee at one's institution, or (f) lay people to whom one will talk about one's work.

\section{CRITERION 2: LIKELIHOOD OF ACCEPTANCE}

Definition: Perception of the probability of a certain article being published in a certain journal

Specific considerations: This crucial point requires both an impartial view of one's paper (a skilled task) and a very good and current knowledge of the rejection rate, how the target journal is managed, its mission, and the sequence of publications on the same topic. Considerations should include appropriateness of style/manuscript type and content, ability to apply results to the journal's audience, a past record with the target journal, and personal acquaintance with the Editor. Generally speaking, the difficulty in being accepted increases as a journal's prestige increases. Achievement of personal objectives thus demands careful weighting of all criteria.

Instructions: A subjective assessment must be made for each journal on a scale of 0 to 10 that takes account of factors such as those above described. The journal considered to be most advantageous must be assigned a score of 10 and the other journals proportionally lower scores.

Data sources: This is a criterion with many subjective and even unknowable aspects, but it is helpful to know the aims, target and rejection rate of potential journals; these can often be gleaned from the instructions for authors, which are usually available on the Web.

\section{CRITERION 3: QUALITY OF REVIEW}

Definition: Perception of the quality of the review process and that, whatever the outcome, there will be a benefit in terms of useful suggestions.

Specific considerations: The helpfulness of the suggestions contained in the reviewed manuscript is linked to the ability of the editorial staff and pool of referees used by the journal, and concerns both the text and statistics/tables. Quality revisions make for good working relations, opportunities for professional growth, and improved articles. This criterion may warrant higher esteem than some authors might accord it, particularly for first submissions.

Instructions: As with the prior criteria, a subjective assessment must be made for each journal on a scale of 0 to 10 that takes account of factors such as those described above, and the journal considered to be most advantageous should be assigned a score of 10 and the other journals proportionally lower scores.

Data sources: This is a subjective criterion chiefly based on one's own, or one's colleagues' experiences, perceptions, and expectations.

\section{CRITERION 4: RAPIDITY OF TURNAROUND}

Definition: Speed with which the editor of a journal passes judgement on an article. 
Table 2. Example of Priority Scores calculated for three journals $(a, b, c)$ before submitting an article.

\begin{tabular}{|c|c|c|c|c|c|c|c|}
\hline \multirow[b]{2}{*}{ Criterion } & \multirow[b]{2}{*}{$\begin{array}{l}\text { Criterion } \\
\text { weight (W) }\end{array}$} & \multicolumn{2}{|c|}{ Journal (a) } & \multicolumn{2}{|c|}{ Journal (b) } & \multicolumn{2}{|c|}{ Journal (c) } \\
\hline & & $\begin{array}{l}\text { Criterion } \\
\text { Score }(\mathrm{S})\end{array}$ & WS & $\begin{array}{l}\text { Criterion } \\
\text { Score }(S)\end{array}$ & WS & $\begin{array}{l}\text { Criterion } \\
\text { Score }(\mathrm{S})\end{array}$ & WS \\
\hline Prestige & 10 & 10 & 100 & 8 & 80 & 3 & 30 \\
\hline $\begin{array}{l}\text { Likelihood of } \\
\text { acceptance }\end{array}$ & 7 & 5 & 35 & 8 & 56 & 10 & 70 \\
\hline $\begin{array}{l}\text { Quality } \\
\text { of review }\end{array}$ & 4 & 9 & 36 & 10 & 40 & 1 & 4 \\
\hline $\begin{array}{l}\text { Turnaround } \\
\text { rapidity }\end{array}$ & 5 & $\begin{array}{l}10 \\
\text { (2 weeks) }\end{array}$ & 10 & $\begin{array}{l}50 \\
\text { (10 weeks) }\end{array}$ & 10 & $\begin{array}{l}5 \\
\text { (4 weeks) }\end{array}$ & 25 \\
\hline Intangibles & 2 & 5 & 10 & 10 & 20 & 2 & 4 \\
\hline Total Score & & & 231 & & 206 & & 133 \\
\hline
\end{tabular}

Specific considerations: Another critical parameter is the speed with which the journal reviews manuscripts and gives authors decisions. Many journals seem to give increasing attention to this factor, thereby shortening response times, in some cases taking advantage of communication by fax or entirely electronic communications. Some hard copy and on-line journals offer the interesting opportunity of following the revision process via Internet. Waiting times of 6 months and over, which still unfortunately occur, are becoming even less acceptable, with the result that many authors are becoming more able to act on a preference for journals that provide rapid reviews and decisions.

Instructions: Whenever possible, an objective assessment must be made for each journal on a scale of 0 to 10 . The journal considered to be most rapid must be assigned a score of 10 and the other journals proportionally lower scores. If data are not available, this criterion cannot be applied.

Data sources: The rapidity of turnaround is sometimes indicated by the journal in the section of the Information for Authors that outlines their peer review process. In other cases, this information is based on one's own experience or that of colleagues, and can occasionally be inferred from acknowledgement letters.

\section{CRITERION 5: INTANGIBLES}

Definition: Perception of other mainly subjective advantages, such as an aesthetic preference for a certain journal, acquaintance with an editor, etc.

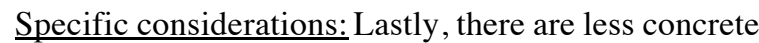
factors that explicitly consider personal taste. These elements include personal preference for a certain journal, its editorial and graphical style, a liking for the editor or a member of the editorial board, or the desire to diversify the journals in which one publishes.

Instructions: A subjective assessment must be made for each journal on a scale of 0 to 10 that takes account of factors such as those above described. The journal considered to be most advantageous must be assigned a score of 10 , and the other journals proportionally lower scores.

Data sources: It is a subjective criterion.

\section{Step 5: Calculating priorities}

The final choice of journal is made at the end of the process, using a simple mathematical prioritycalculating formula. After weighting and rating the criteria, the total score can be calculated for each journal included in the author's list of candidates. Practically speaking, each criterion score is adjusted by the weight given to each criterion.

Let us consider a finite number of candidate journals $(\mathrm{a}, \mathrm{b}, \mathrm{c}, \ldots)$ based on a finite number of criteria $(1,2,3,4,5)$ which are given criterion weights (W1, W2, W3, W4, W5); these criteria and their weights are the same for all the candidate journals. Each journal also receives criterion scores (S1, S2, S3, S4, S5) which are calculated for each criterion for each alternative journal.

The formula to calculate the priority score for journal 
(a) would therefore be as follows: Priority score for journal (a) $=[($ criterion weight of criterion 1$) \mathrm{x}$ (criterion score attributed to journal a for criterion 1)] + [(criterion weight of criterion 2) x (criterion score attributed to journal a for criterion 2) $]+[$ (criterion weight of criterion 3) $\mathrm{x}$ (criterion score attributed to journal a for criterion 3)] + [(criterion weight of criterion 4) $\mathrm{x}$ (criterion score attributed to journal a for criterion 4$)]+[$ (criterion weight of criterion 5) $\mathrm{x}$ (criterion score attributed to journal a for criterion 5) $]=$ [W1 $x \mathrm{~S}(1 \mathrm{a})]+[\mathrm{W} 2 \times \mathrm{S}(2 \mathrm{a})]+[\mathrm{W} 3 \times \mathrm{S}(3 \mathrm{a})]+[\mathrm{W} 4 \times$ $\mathrm{S}(4 \mathrm{a})]+[\mathrm{W} 5 \times \mathrm{S}(5 \mathrm{a})]$.

Each of the 5 criteria receives a score based on its merits vs. those of the other candidate journals (see Table 2). Let's suppose for journal (a) that the maximum criterion score is given to "Prestige" (i.e. a score of 10), a score of 5 to "Likelihood of acceptance", a score of 5 to "Intangibles", a score of 9 to "Quality of review", and a score of 10 to "Rapidity of turnaround". Each of these scores is multiplied by the weight previously attributed to each criterion (for this example, let's assign: "Prestige" $=10 ; \quad$ "Likelihood of acceptance" $=7$, "Intangibles" $=2$; "Quality of review"=4; "Rapidity of turnaround" $=5$ ). Hence, the total score for journal (a) becomes: WS $=(10 \times 10)+(7 \times 5)+(2 \times 5)+(4 \times 9)+$ $(5 \times 10)=100+35+10+36+50=231$. Priority scores are then calculated for the other candidate journals in the list (b, c, d, and e), which are then ranked, and the journal with the highest score gets priority of submission.

Given this high score, an author may choose to first submit the paper to journal (a). If the paper is rejected by journal (a), the author, preferably after revision based on reviews, may submit the article to journal (b), which presents the score immediately below. In the event of rejection by (b), the author may behave in two ways. S/he may decide to submit the manuscript to journal (c) or, since journal (c)'s ranking is well below that of journal (a) (231) and (b) (206), may opt to repeat the assessment process with additional candidate journals. These candidate journals for reassessment (c, $\mathrm{d}$, e) must be considered according to the first-time assessment procedure, as described above.

\section{Comment on the model}

The proposed method is drawn in part from the Donaldson \& Sox model for priority setting for the
Office of Health Technology Assessment of the Agency for Healthcare Research and Quality, designed to determine which of the countless available health care technologies should be subject to systematic yearly assessment (5). Our model considerably simplifies theirs, particularly mathematically, and is (to the best of our knowledge) the only published method for objective determination of journal selection methodology.

This novel approach to journal selection is a quantitative model. It is suggested because of its explicitness, and its ability to bring together different concepts and units of measurement in the same scale. It clarifies selection criteria, acknowledging their definitions, main characteristics, importance, and subjectivity. Subjective criteria may still prevail; while this method does not provide objective standards, it begins to pragmatically and explicitly outline the subjective and objective criteria for choosing the journal to which one submits a manuscript for publication. While some might find it rigid, timeconsuming, or overly quantitative, the method could be useful both for experienced authors who wish to make more explicit the criteria they use for deciding manuscript destinations, and for more junior authors whose lack of experience might benefit from a rational guide.

Mariotto, Aldo, M.D.

Medicine Service, Head, Health Authority No. 2, "Isontina", Italy

Frank, Erica, M.D., M.P.H.

Associate Professor and Vice Chair, Department of Family and Preventive Medicine, Emory University School of Medicine

\section{REFERENCES}

1. Frank E. Authors' Criteria for Selecting Journals. JAMA 1994 ;272:163-164.

2. Hojat M, Gonnella JS, Caelleigh AS. Impartial Judgment by the "Gatekeepers" of Science: Fallibility and Accountability in the Peer Review Process. Adv Health Sci Educ Theory Pract 2003;8:75-96.

3. http//www.isinet.com/isi/

4. http//www.science.komm.at

5. Donaldson MS, Sox HC. Setting Priorities for Health Technology Assessment: A Model Process. Washington, DC: National Academy Press, 1992.

\footnotetext{
Aldo Mariotto is a Medical Doctor graduated from Padua University and recently specialized in Hygiene and Preventive Medicine. His research interests include waiting lists, appropriateness and partnership. Erica Frank, MD, MPH, is a tenured Associate Professor, and Vice Chair for Academic Affairs of the Department of Family and Preventive Medicine, at Emory University School of Medicine. Following a transitional internship at the Cleveland Clinic, she was residency (Yale, 1990) and fellowship (Stanford, 1993) trained, and board certified in preventive medicine. While primarily a researcher on physicians' personal and clinical prevention habits, she directs Emory's Preventive Medicine Residency Program, has an indigent clinical practice in cholesterol management, and is the Education Coordinator for the WHO Health InterNetwork.
} 